\title{
Results of Treatment of Displaced Midshaft Clavicle Fractures in Adults by Open Reduction And Internal Fixation - A Case Series
}

\author{
Herman Conrad Frank Associate Professor, Tridip Bharali Registrar, Rajarshi \\ Roy Registrar, Anshuman Dutta Pg Trainee, Hrishikesh Bharali Pg Trainee, \\ Nilim K Deka \\ Department Of Orthopaedics, Gauhati Medical College And Hospital, Guwahati, Assam
}

\begin{abstract}
Introduction: Open reduction and internal fixation is a standard modality of treatment in widely displaced midshaft fractures of clavicle in adults. We report the result of a prospective study of thirty two patients, who were treated by open reduction and internal fixation.

Methodology: In a prospective study, 32 cases of displaced fractures in adults were treated with open reduction and internal fixation. The age group of the patients were above 16 years. Cases were followed up for an average of eight months post operatively.

Results: Assessed as per CONSTANT score for functional results at the end of 6-8 months of follow up. Excellent result was seen in around $86.03 \%$ patients and good results seen in $13.97 \%$ patients.

Conclusion: Open reduction and internal fixation is a standard method for the management of displaced midshaft clavicle fractures in adults. It not only obviates many of the complications of non-operative treatment but also gives better functional results.
\end{abstract}

Keywords: Clavicle fractures, open reduction, functional outcome.

\section{Introduction}

Clavicle fractures are common injuries in young, active individuals, especially those who participate in activities or sports where high-speed falls (bicycling, motorcycles) or violent collisions (football, hockey) are frequent, and they account for approximately $2.6 \%$ of all fractures[1]. The majority of clavicular fractures $(80 \%$ to $85 \%$ ) occur in the midshaft of the bone[1]. Distal third fractures are the next most common type (15\% to $20 \%$ ), and they tend to occur in more elderly individuals from simple falls. Medial third fractures are the rarest $(0 \%$ to $5 \%)$, perhaps due to the difficulty in accurately imaging (and identifying) them[2].

Older studies suggested that a fracture of the shaft of the clavicle, even when significantly displaced, was an essentially benign injury with an inherently good prognosis when treated nonoperatively[3]. However, modern studies have demonstrated functional deficiencies in regards to range of shoulder movement and efficiency to perform heavy physical activity and higher nonunion rates with conservative treatment for displaced clavicle fractures compared to previous reports[4]. Patients are increasingly showing an intolerant attitude towards prolonged immobilization. Even their inacceptability towards the anticipation of possible cosmetic deformity following conservative treatment is increasing indications for surgical fixation of this fracture.

Immobilisation using a figure-of-eight bandage or a simple sling is generally accepted as the standard treatment for non-displaced fractures and majority of displaced fractures. However for widely displaced $(>2 \mathrm{~cm})$, shortening $(>2 \mathrm{~cm})$, comminuted, segmental, or open fractures, or with clinical deformity open reduction and plate fixation is widely accepted as the standard treatment $[5,6]$. Criteria for conservative \& operative treatment is not clearly defined, so counselling with patients should be done outlining the relative risks of operative fixation eventually creating a cosmetic scar versus nonoperative treatment. The goals of surgical management include correction and maintenance of alignment, union, and early functional range of shoulder movement eventually increasing the efficiency for heavy physical activity on a long term basis[7,8,9]. The aim of our study was to evaluate the functional results of open reduction and precontoured clavicular locking compression plate fixation in the treatment of displaced clavicle fractures in adults done by relatively inexperienced orthopaedic surgeons under supervision of a senior surgeon. The reason for doing such a study was that in our centre, which is a tertiary hospital in northeast admitting large number of orthopaedic emergencies each year, two thirds of the surgeons on call have less than four years experience after post-graduation.

\section{Materials And Methods}

A prospective study was carried out for a total of 32 cases of displaced clavicle fractures of adults aged between 16-60 yrs attending the OPD and Emergency department of Orthopaedics, Gauhati Medical 
College \& Hospital who met the inclusion and exclusion criteria outlined below. All the cases were followed up for a minimum period of six months. In our study patients who gave consent, patient aged between 16 to 60 yrs, closed fractures, with no associated open injuries in the same limb and intact neurological and vascular status of the affected limb, ipsilateral shoulder, wrist and elbow and fingers functionally good enough, so as not to exert an adverse effect on the rehabilitation process and who met the medical standards for surgery were included.

The patients excluded were whose parents/guardians did not give consent, patients aged <16yrs and $>60 y$ rs, patients unable to take part in post-operative rehabilitation, not fit for surgery/anaesthesia, open fractures, or fractures with history of trauma $>21$ days.

After appropriate radiological and pre-operative investigations the individual was posted for surgery.

Taking the patient in beach chair position and after proper shaving, scrubbing, cleaning and draping clavicle is opened through superior approach and antero-superior plating is done with a precontured locking compression plate after anatomical reduction. Proper care is taken to drill and put screws to avoid inadvertent injury to neurovascular structures below the clavicle. Lag screws were inserted if required. The myofascial layer and the subcutaneous layer is closed meticulously after securing haemostasis.

Post operatively the arm is placed in a arm pouch and the patient is allowed early active motion in the form of pendulum exercises. Patients were discharged usually after $2^{\text {nd }}$ or $3^{\text {rd }}$ post-operative day when reduction of pain and oedema occured. Patients were followed up at 10-15 days after which stitches were removed. The pouch is then discarded and full range-of-motion exercises are instituted. Clinical evaluation was done for active and passive range of motion, neurovascular status, superficial and deep infection and necessity to re-operate. Clinical evaluation was done according to CONSTANT score [5].

Further follow ups were done on six week, three month and six month after the operative procedure. Patients were assessed for full function, minor limitation of function and major loss of function. Check X-rays were taken immediate post operative, at six weeks, three months, six months and twelve months.

\section{Results}

The patients were personally reviewed with clinical and radiological evaluation with an average follow-up of 8.2 months (range six - sixteen months). There were 32 patients with a mean age of 28.4 years and youngest patient was 18 years and the oldest patient was 54 years. The most common mechanism of injury was road traffic accidents $(64.51 \%)$. Males $(72.6 \%)$ were more more commonly involved than females $(27.4 \%)$. Left side $(77.40 \%)$ was more commonly injured than right side $(22.60 \%)$. Most patients were operated within the first two days. Complications included 2 cases of superficial infection and no deep infection. 3 cases of hardware irritation. There were no cases of brachial plexus irritation.

The functional results were found to be excellent according to CONSTANT score[5] in 86.03\% and good in $13.97 \%$. There were no poor results.

\section{Discussion}

Clavicle fractures are one of the most common fractures around the shoulder in young adults[1]. Most undisplaced and minimally displaced fractures are commonly treated by immobilization using a figure-of-eight bandage or a simple sling. [10] The treatment of more severely displaced fractures remains controversial. The aim of our study was to develop a simple algorithm of treatment to provide the best functional and cosmetic result even when undertaken by less experienced surgeons and the simplest follow-up regime. The conservative management of displaced fractures of clavicle is known to lead to unacceptable reduction with displacement leading to cosmetic deformity and nonunion as mentioned by Zlowodzki et al [11] and Robinson et al [12]. In our study, the union rate was $100 \%$. In 2 cases there was gross comminution where we had to put autologous iliac crest graft. Superficial infection occurred in 2 cases which is comparable to Zlowodzki et al [11]. Infection was treated with antibiotics and regular dressing. However, the loss of range of motion was greater in these 2 patients, compared to those without infection.

\begin{tabular}{|l|l|}
\multicolumn{1}{c}{ Infection } \\
\hline SERIES & INFECTION \\
\hline Zlowodzki et al [11] & 4.4 \\
\hline Present study & 6.25 \\
\hline
\end{tabular}

Zlowodzki et al performed a meta-analysis of all series of displaced midshaft fractures and found the nonunion rate following operative treatment was $2.2 \%$. In the most recently published randomized trial comparing operative versus nonoperative treatment, Virtanen et al.[13] reported union of all fractures in the plate fixation group with low complication rate. 


\begin{tabular}{|l|l|}
\multicolumn{2}{c}{ Nonunion } \\
\begin{tabular}{|l|l|}
\hline Series & Nonunion \\
\hline Zlowodzki Et Al [11] & 2.2 \\
\hline Virtanen Et Al.[13] & 0 \\
\hline Present Study & 0 \\
\hline
\end{tabular}
\end{tabular}

\section{Associated Injuries}

In our study 4 cases had same sided single rib fracture, 3 cases had multiple rib fractures, 1 female case of blunt trauma abdomen, 1 case of scaphoid fracture on opposite side, and 1 case of fracture of shaft of femur on same side.

There was mild hardware irritation in 2 cases, and implants were removed after radiological and clinical union occurred. There were no cases of refracture in our study. At the end of three months we evaluated our results for each patient according to CONSTANT score [5]. Overall we obtained "excellent" results in 86.03\%; and "good" in $13.97 \%$ cases. There were no poor results.

\section{Conclusion}

From our study we concluded that open reduction and plate fixation can be the treatment of choice in widely displaced clavicle fractures in adults. This method can be done even by relatively inexperienced young orthopaedic surgeons with satisfactory functional outcome.

Financial support and sponsorship: nil
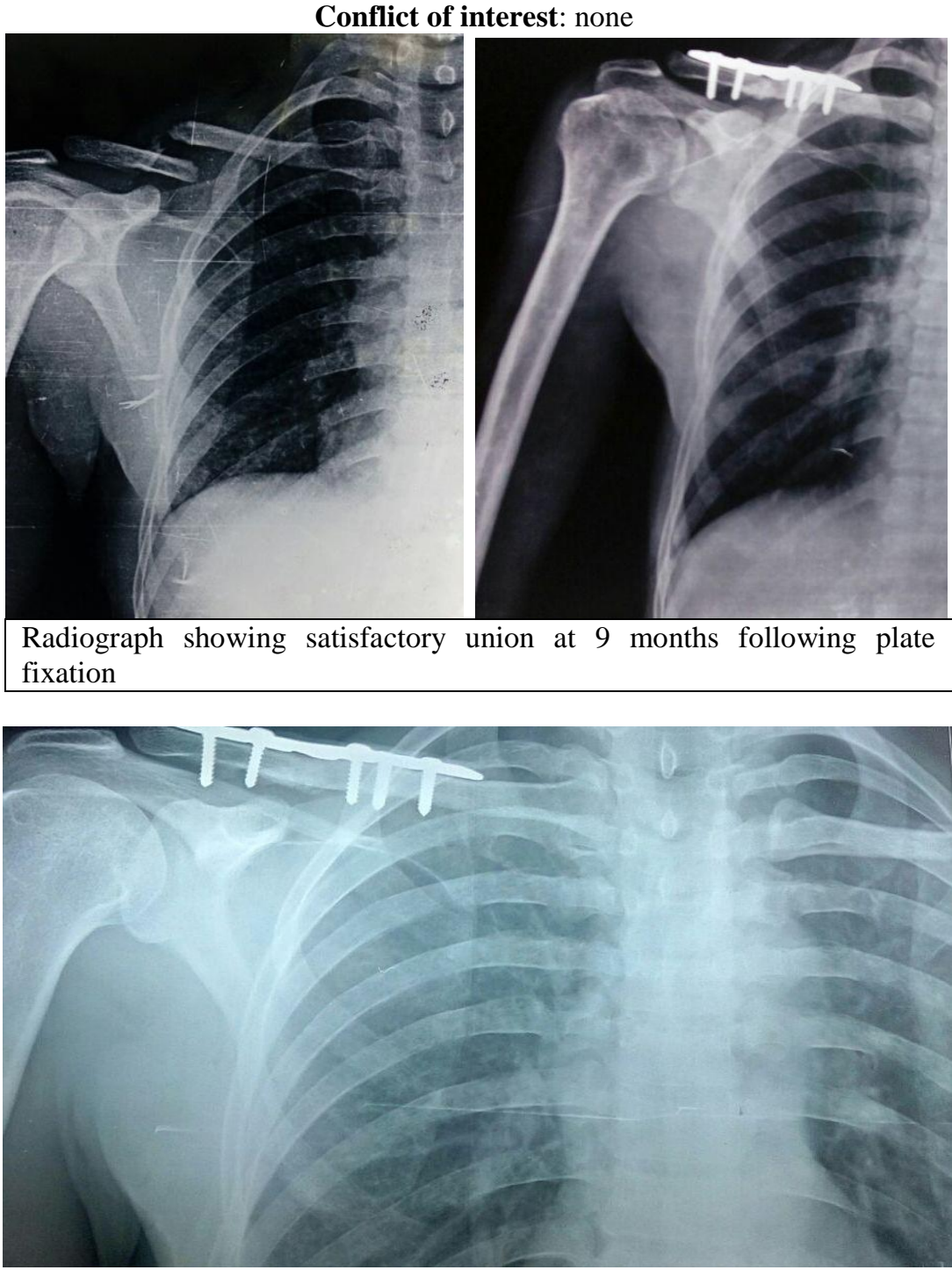

Radiograph showing union at the end of 18 months 

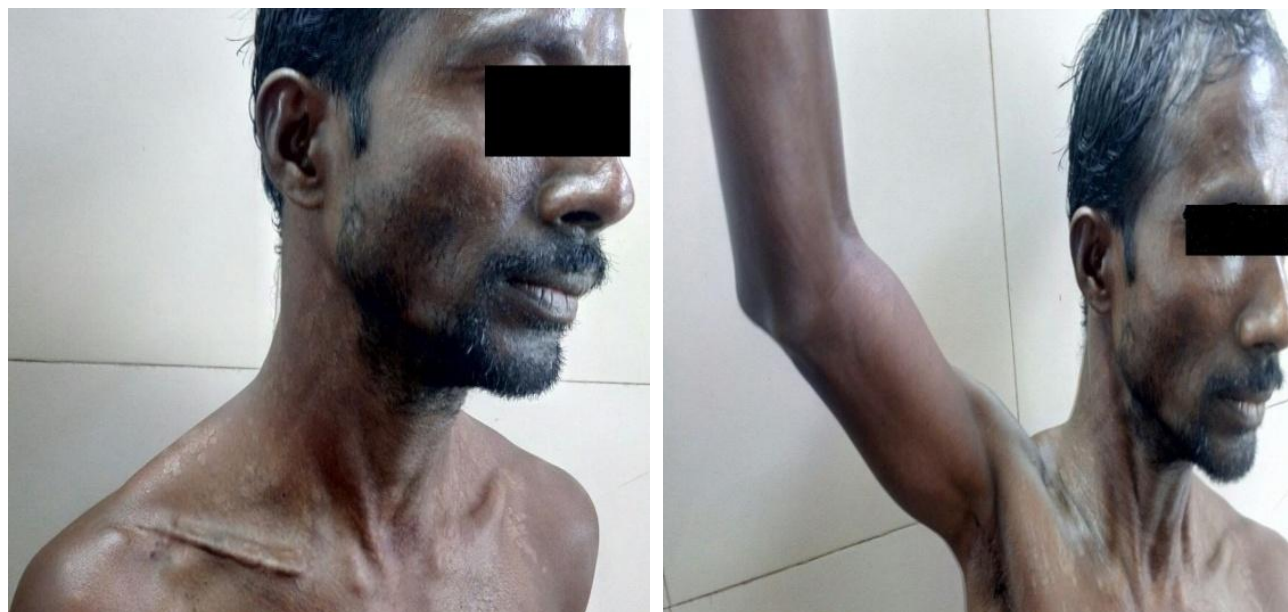

Patient showing hardware prominence but satisfactory shoulder movement

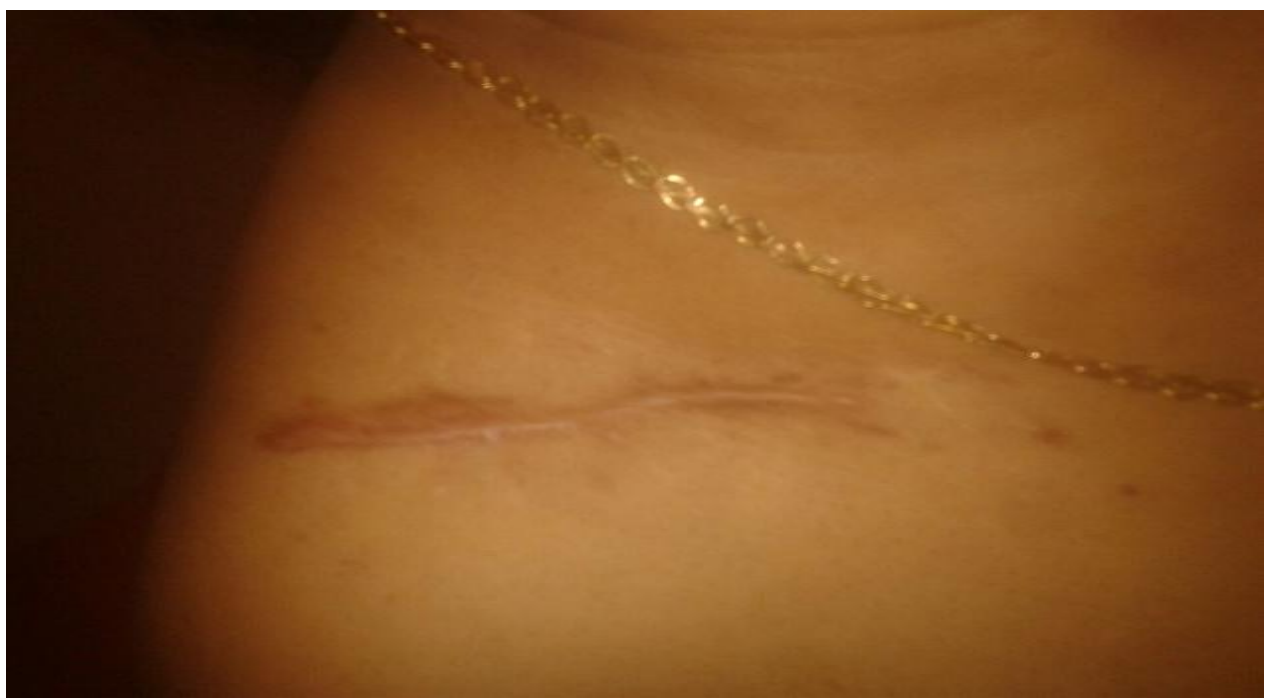

Post surgical scar hypertrophy in a female patient
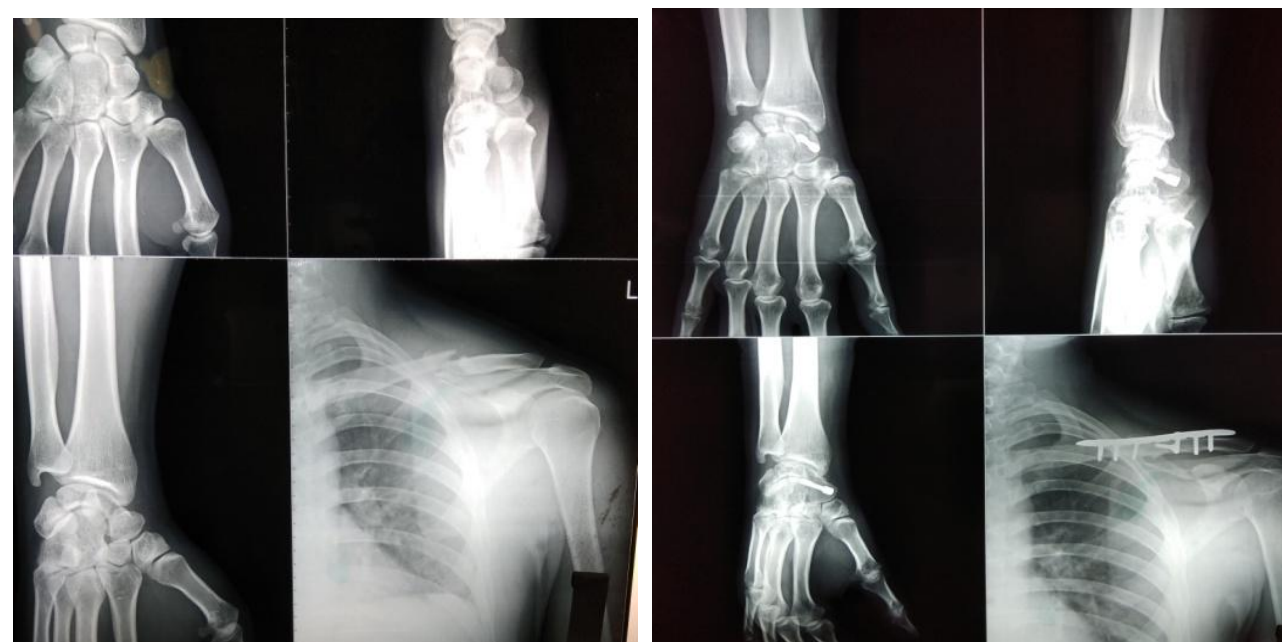

Radiograph showing fixation of clavicle fracture with associated opposite side scaphoid fracture 


\section{References}

[1]. Michael D. McKee. Clavicle fractures. In Heckman JD, Court-Brown CM. Rockwood and Green's Fractures in Adults. $8^{\text {th }}$ edition, vol 1:1427-1474.

[2]. Seo GS, Aoki J, Karakida O, et al. Nonunion of a medical clavicular fracture following radical neck dissection: MRI diagnosis. Orthopedics. 1999;22(10):985-986.

[3]. Neer CS. Fractures of the Clavicle. In: Rockwood CA, Green DP, eds. Fractures in Adults. 2nd ed. Philadelphia, PA: JB Lippincott; 1984:707-713

[4]. Gossard JM. Closed treatment of displaced middle-third fractures of the clavicle gives poor results [Letter to the editor]. J Bone Joint Surg Br. 1998;80(3):558.

[5]. Canadian Orthopaedic Trauma Society. Nonoperative treatment compared with plate fixation of displaced midshaft fractures. A multicenter, randomized clinical trial. J Bone Joint Surg Am. 2007;89(1):1-10.

[6]. Judd DB, Pallis MP, Smith E, et al. Acute operative stabilization versus nonoperative management of clavicle fractures. Am J Orthop. 2009;38(7):341-345.

[7]. McKee RC, Whelan DB, Schemitsch EH, et al. Operative versus nonoperative care of displaced midshaft clavicular fractures: A meta-analysis of randomized clinical trials. J Bone Joint Surg Am. 2012;94(8):675-684.

[8]. Poigenfurst J, Rappold G, Fischer W. Plating of fresh clavicular fractures: Results of 122 operations. Injury. 1992;23(4):237-241.

[9]. Craig EV. Fractures of the clavicle. In: Rockwood CA, Green DP, Bucholz RW, Heckman JD, eds. Rockwood and Green's Fractures in Adults. Philadelphia, PA: Lippincott-Raven; 1996:1109-1161.

[10]. Andersen K, Jensen PO, Lauritzen J. Treatment of clavicular fractures. Figure-of-eight bandage versus a simple sling. Acta Orthop Scand. 1987;58(1):71-74.

[11]. Zlowodzki M, Zelle BA, Cole PA, et al. Treatment of acute midshaft clavicle fractures: Systematic review of 2144 fractures: On behalf of the Evidence-Based Orthopaedic Trauma Working Group. J Orthop Trauma, 2005;19(7):504-507.

[12]. Robinson CM, Court-Brown CM, McQueen MM, et al. Estimating the risk of nonunion following nonoperative treatment of a clavicle fracture. J Bone Joint Surg Am. 2004;86- A(7):1359-1365.

[13]. Virtanen KJ, Remes V, Pajarinen J, et al. Sling compared with plate osteosynthesis for treatment of displaced midshaft clavicular fractures: A randomized clinical trial. J Bone Joint Surg Am. 2012;94(17):1546-1553. 